\title{
Limited Exercise Capacity in Patients with Systemic Sclerosis: Identifying Contributing Factors with Cardiopulmonary Exercise Testing
}

\author{
Nihal Martis, Viviane Queyrel-Moranne, David Launay, Rémi Neviere, Jean-Gabriel Fuzibet, \\ Charles-Hugo Marquette, and Sylvie Leroy
}

ABSTRACT. Objective. Exercise limitation in patients with systemic sclerosis (SSc) is often multifactorial and
related to complications such as interstitial lung disease (ILD), pulmonary vasculopathy (PV), left
ventricular dysfunction (LVD), and/or peripheral/muscular limitation (PML). We hypothesized that
cardiopulmonary exercise testing (CPET) could not only suggest and rank competing etiologies, but
also highlight peripheral impairment.

Methods. Clinical, resting pulmonary function testing, and CPET data from patients with SSc referred for exercise limitation between October 2009 and November 2015 were retrospectively analyzed in this bi-center study. Patients were categorized as having ILD, PV, LVD, and/or PML based on CPET response patterns and the diagnoses were matched with results from the reference investigations. The latter consisted of transthoracic echocardiography, chest computed tomography scan, and right heart catheterization (RHC).

Results. Twenty-seven patients presented with CPET profiles consistent with ILD ( $\mathrm{n}=16)$, PV $(\mathrm{n}=15)$, LVD $(\mathrm{n}=5)$, and PML $(\mathrm{n}=19)$. None of the subjects had a normal CPET profile. There was a statistically significant negative correlation between resting DLCO, on the one hand, and dead space to tidal volume ratio and alveolar-arterial gradient $\left[\mathrm{P}(\mathrm{Ai}-\mathrm{a}) \mathrm{O}_{2}\right]$ on the other $(\mathrm{p}<0.005)$. CPET identified $90 \%$ of patients with a mean pulmonary arterial pressure at rest $\geq 21 \mathrm{mmHg}$ measured by $\mathrm{RHC}(\mathrm{n}=10)$. Peak $\mathrm{P}(\mathrm{Ai}-\mathrm{a}) \mathrm{O}_{2}$, taken independently from other variables, was crucial in distinguishing subjects with ILD from those without ILD ( $\mathrm{p}<0.05)$.

Conclusion. CPET is useful for the characterization of multifactorial exercise limitation in patients with SSc and in identifying SSc-related complications such as ILD and PV. This study also identifies PML as an underestimated cause of exercise limitation. (First Release November 1 2017; J Rheumatol 2018;45:95-102; doi:10.3899/jrheum.161349)

Key Indexing Terms:

EXERCISE TEST SYSTEMIC SCLEROSIS DYSPNEA PULMONARY FIBROSIS MUSCULOSKELETAL PHYSIOLOGICAL PHENOMENA PULMONARY GAS EXCHANGE

From the Service de Médecine Interne, Centre Hospitalier Universitaire (CHU) de Nice, Nice; University of Lille, U995 Lille Inflammation Research International Center (LIRIC), Lille; INSERM, U995, Lille; CHU Lille, Département de Médecine Interne et Immunologie Clinique, Lille;

Centre national de référence maladies systémiques et auto-immunes rares (sclérodermie systémique), Lille; Service d'Explorations Fonctionnelles Respiratoires, CHU de Lille, Lille; FHU OncoAge, Côte d'Azur University, Nice, France.

N. Martis, MD, MS, Service de Médecine Interne, CHU de Nice; V. Queyrel-Moranne, MD, MS, Service de Médecine Interne, CHU de Nice; D. Launay, MD, PhD, Professor of Medicine, Univ. Lille, U995, LIRIC, INSERM U995, CHU Lille, Département de Médecine Interne et Immunologie Clinique, Centre national de référence maladies systémiques et auto-immunes rares (sclérodermie systémique); $R$. Neviere, $M D, P h D$, Professor of Medicine, Service d'Explorations Fonctionnelles Respiratoires, CHU de Lille; J.G. Fuzibet, MD, MS, Professor of Medicine, Service de Médecine Interne, CHU de Nice; C.H. Marquette, MD, PhD, Professor of Medicine, FHU OncoAge, Côte d'Azur University; S. Leroy, MD, FHU OncoAge, Côte d'Azur University.

Address correspondence to Dr. N. Martis, Service de Médecine Interne, CHU de Nice, 151 Route de Saint-Antoine de Ginestière, 06200 Nice,

France.E-mail: martis.n@chu-nice.fr

Accepted for publication August 8, 2017.
Systemic sclerosis $(\mathrm{SSc})$ is a rare connective tissue disease of unknown origin that is characterized by fibrosis of the skin and internal organs, microvasculopathy, and autoimmunity ${ }^{1}$. While respiratory symptoms are rarely present in newly diagnosed forms of the disease, more than $70 \%$ of patients ultimately develop pulmonary involvement ${ }^{2}$. A common symptom in patients with SSc, dyspnea is neither sensitive nor specific for the identification of SSc-related complications such as interstitial lung disease (ILD), pulmonary vasculopathy (PV), left ventricular dysfunction (LVD), and/or peripheral/muscular limitation (PML). The mechanisms of dyspnea in SSc are most often multifactorial and interlinked. Diagnosis is further delayed by patients' adaptation to dyspnea through exercise limitation. ILD and pulmonary arterial hypertension (PAH) are known to be the 2 leading causes of death in patients with $\mathrm{SSc}^{3}$. Early detection is therefore crucial for improving survival in SSc. This, however, requires identifying the underlying etiologies

Personal non-commercial use only. The Journal of Rheumatology Copyright (c) 2018. All rights reserved. 
of exercise limitation because treatment strategies and followup are likely to differ.

An American Thoracic Society/American College of Chest Physicians (ATS/ACCP) statement presents cardiopulmonary exercise testing (CPET) as a "global assessment of the integrative exercise response involving the pulmonary, cardiovascular, hematopoietic, neuropsychologic, and skeletal muscle systems that is not adequately reflected through the measurement of individual organ system function"4. CPET has become a useful tool for the early diagnosis and for the monitoring of treatment efficacy of cardiopulmonary diseases (i.e., chronic obstructive pulmonary disease and ILD). Exercise limitation should be investigated in patients with SSc in whom cardiac, pulmonary, and (vascular or skeletal) peripheral abnormalities are clinically present only on exertion. Previous studies have shown that CPET could help in the early detection of PAH and LVD, and to differentiate these entities ${ }^{5,6,7}$. However, they focused on classifying patients according to gas exchange patterns without necessarily recognizing the effect of competing mechanisms. Further, we aimed to determine the frequency of peripheral impairment (i.e., deconditioning, SSc-related PML, and peripheral vascular disease).

The rationale behind our preliminary study was to assess to what extent the combination of ILD, PAH, LVD, and PML might explain exercise limitation in a given patient with SSc. We therefore hypothesized that CPET could not only identify competing etiologies, but also highlight peripheral impairment. In addition, we sought to validate our hypothesis by comparing our results, whenever possible, with those of reference investigations.

\section{MATERIALS AND METHODS}

Study population and definitions. This collaborative project between the university hospitals of Lille and Nice (France) was to retrospectively analyze data from patients with SSc and dyspnea who underwent CPET from October 2009 to November 2015. The patients all presented with dyspnea for which imaging techniques, pulmonary function tests at rest (PFT), and/or biological markers [i.e., brain natriuretic peptide (BNP), $\mathrm{N}$ terminal-proBNP, hemoglobin, etc.] were unable to easily identify a cause for exercise limitation or the main limiting factor. Infectious states were ruled out prior to CPET. Dyspnea was graded according to the New York Heart Association and/or the World Health Organization functional scales. All patients met the 2013 American College of Rheumatology/European League Against Rheumatism (ACR/EULAR) classification criteria for SSc. They were further classified according to limited or diffuse cutaneous subsets according to LeRoy and Medsger ${ }^{8,9}$. Limited cutaneous SSc $(\mathrm{lcSSc})$ is defined by either limited skin thickness restricted to the fingers, hands, and/or forearms and/or face, or the absence of skin thickness. On the other hand, diffuse cutaneous $\mathrm{SSc}(\mathrm{dcSSc})$ refers to the involvement of regions proximal to the elbows and knees and/or the torso. The extent of the cutaneous involvement was assessed using the modified Rodnan score ${ }^{10}$. The flowchart (Figure 1) summarizes the recruitment process. Patients with hemoglobin levels of $<10.5 \mathrm{~g} / \mathrm{dl}$ were not included in our study.

Resting PFT and 6-min walk test (6MWT). Spirometry, plethysmography, and DLCO were conducted prior to CPET. Measurements of forced vital capacity, forced expired volume in $1 \mathrm{~s}$, and alveolar volume complied with ATS/European Respiratory Society (ERS) standards ${ }^{11}$. The best value from a minimum of 3 measurements was used. Additionally, DLCO values were systematically adjusted for hemoglobin levels. The transfer coefficient (KCO) is the value of the DLCO divided by the VA. All predicted values are those recommended by the ATS/ERS study groups ${ }^{12,13}$.

When available, data from the most recent standardized 6MWT performed prior to CPET were recorded. The 6MWT were conducted based on the 2002 ATS guidelines ${ }^{14}$. Performances were expressed in meters (absolute value), but also as percentages of predicted distances calculated according to the reference equations by Enright and Sherrill ${ }^{15}$.

CPET. CPET followed the 2001 ATS/ACCP guidelines and only subjects without contraindications for CPET were tested ${ }^{4}$. System calibration was performed prior to testing, in accordance with the established protocols ${ }^{16}$. A maximal incremental protocol was used on a computer-controlled cycle ergometry (Ergoline 800, SensorMedics, Logiciel Exp'Air, Medisoft; surface electrocardiograph: Quinton Q710sx, Quinton Inc.). All subjects were given a 2-min warmup phase at $10 \%$ of their predicted maximal work rate. The objective was to sustain a 10-min effort. Respiratory rate, arterial oxygen saturation $\left(\mathrm{SpO}_{2}\right)$, and blood pressure were monitored from warmup until recovery.

Expired gases were analyzed throughout with an Ergocard Clinical system (Medisoft). A 12-lead surface electrocardiograph (ECG) provided continuous cardiac monitoring. $\mathrm{SpO}_{2}$ was measured by a pulse oximetry probe placed on the earlobe. Arterial blood gas sampling (ABG) was obtained by arterial or capillary access. The alveolar-arterial gradient or $\mathrm{P}(\mathrm{Ai}-\mathrm{a}) \mathrm{O}_{2}$ was calculated using arterial partial pressure of oxygen $\left(\mathrm{p}_{\mathrm{a}} \mathrm{O}_{2}\right)$ and carbon dioxide $\left(\mathrm{p}_{2} \mathrm{CO}_{2}\right)$ values from $\mathrm{ABG}$ at peak exercise (in room air). Alveolar oxygen pressure $\left(\mathrm{P}_{\mathrm{A}} \mathrm{O}_{2}\right)$ was defined by the simplified gas equation:

$$
\mathrm{P}_{\mathrm{A}} \mathrm{O}_{2}=\mathrm{FiO}_{2} \times(\mathrm{Pb}-47)-\left(\mathrm{p}_{\mathrm{a}} \mathrm{CO}_{2} / \mathrm{RER}\right)
$$

where $\mathrm{FiO}_{2}$ is the fraction of inspired oxygen, $\mathrm{Pb}$ is the barometric pressure, and RER is the respiratory exchange ratio. Peak $\mathrm{P}(\mathrm{Ai}-\mathrm{a}) \mathrm{O}_{2}$ higher than 35 $\mathrm{mmHg}$ was considered abnormal ${ }^{4}$.

Continuous recordings were done of end-tidal oxygen and carbon dioxide, oxygen uptake $\left(\mathrm{VO}_{2}\right)$, carbon dioxide output $\left(\mathrm{VCO}_{2}\right)$, and the $\mathrm{RER}$. The modified Bohr equation was used to calculate the dead space to tidal volume ratio $(\mathrm{Vd} / \mathrm{Vt})$. Also studied were ratios of minute ventilation to maximal voluntary ventilation, $\mathrm{HR}_{\text {peak }}-\mathrm{HR}_{\text {rest }}$ to $\mathrm{VO}_{2 \text { peak }}-\mathrm{VO}_{2 \text { rest }}$ (or $\Delta \mathrm{HR} / \Delta \mathrm{VO}_{2}$ ), with $\mathrm{HR}$ as heart rate, and the oxygen pulse. The oxygen pulse is the ratio between oxygen uptake $\left(\mathrm{VO}_{2}\right)$ and HR derived from Fick's equation:

$$
\mathrm{VO}_{2} / \mathrm{FC}=\mathrm{SV} \times \mathrm{D}[\mathrm{a}-\mathrm{v}] \mathrm{O}_{2}
$$

where $\mathrm{SV}$ is the stroke volume and $\mathrm{D}[\mathrm{a}-\mathrm{v}] \mathrm{O}_{2}$ the arteriovenous oxygen difference. Predicted values were calculated from reference equations ${ }^{17,18}$ The ventilatory threshold (VeT) was identified graphically using the ventilatory equivalents method and/or the simplified "V-slope" method 19,20

Patients were all encouraged to give a maximal effort so as to reach physiologic limitation, defined by 1 or more of the following criteria: a peak oxygen $\left(\mathrm{VO}_{2 \text { peak }}\right) 2$-min plateau, breathing reserve $<15 \%, \mathrm{HR}_{\text {peak }}$ of more than $90 \%$ of predicted, peak lactatemia $>7 \mathrm{mEq} / \mathrm{l}, \mathrm{VE} / \mathrm{VO}_{2 \text { peak }}>35$ or RER $>1.15$, peak metabolic acidosis (with $\mathrm{pH} \leq 7.3$ ), and/or patient exhaustion (Borg scale $\geq 7$ ). Predicted maximal HR was estimated by the following equation:

$$
210-0.65 \times \text { [subject's age in yrs] }
$$

Early termination of CPET reflected the accepted indications (i.e., chest pain suggestive of ischemia, ischemic ECG changes, hypertension, respiratory failure, etc. $)^{4}$. $\mathrm{VO}_{2 \text { peak }}$ was selected based on the highest values obtained from any 20 -s measurement period ${ }^{21,22}$.

Categorizing subjects according to cardiopulmonary exercise response patterns. For the purpose of our study, exercise response patterns refer to

Personal non-commercial use only. The Journal of Rheumatology Copyright $\odot$ (2018. All rights reserved 


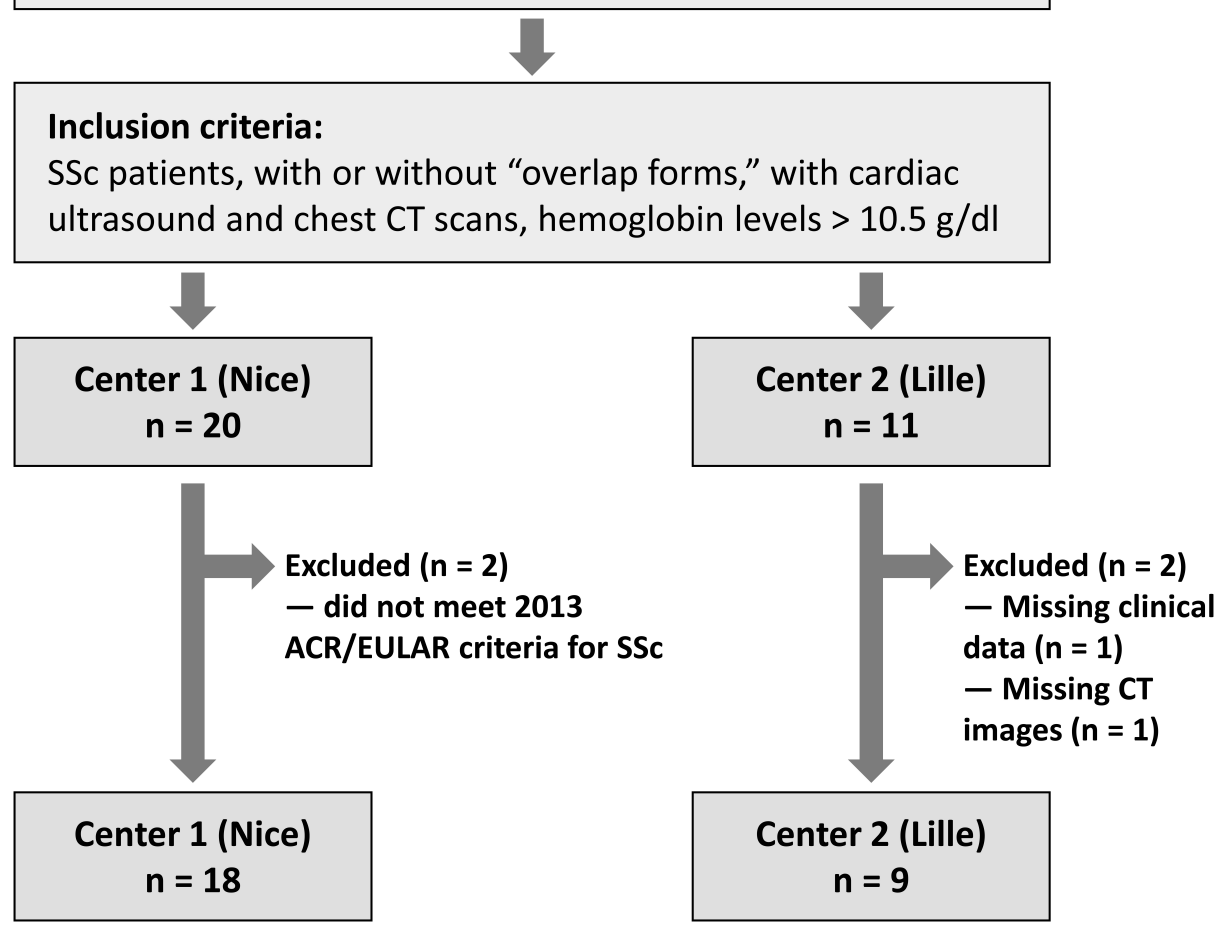

Figure 1. Study flowchart. CPET: cardiopulmonary exercise testing; SSc: systemic sclerosis; CT: computed tomography; ACR/EULAR: American College of Rheumatology/European League Against Rheumatism.

potential etiological diagnoses and patients were therefore classified as having ILD, PAH, LVD, and/or PML. Each patient was classified based on the diagnoses reported at the time of the examination. Diagnostic algorithms formulated by Wasserman, et al were used ${ }^{22}$. The progressive increase in dead space suggested pulmonary vascular disease in the absence of a high respiratory rate. Further, a low oxygen pulse value led to the assumption that the left ventricular ejection fraction was altered. Transthoracic echocardiogram (TTE) was used to distinguish between low oxygen delivery and impaired oxygen extraction. Each case was subsequently reassessed by an expert respiratory specialist who was blinded to the initial diagnoses. Disagreement occurred in only 1 case and was resolved by a re-read from a second expert respiratory specialist.

Imaging techniques and right heart catheterization (RHC). Computed tomography (CT) scanning of the thorax was carried out in all patients and was used to diagnose ILD. The staging system by Goh, et al was used to classify disease as either limited or extensive based on an extent threshold of $20 \%{ }^{23}$. Cardiac MRI was not always performed.

The decision to carry out RHC was based on the modified diagnostic algorithm by Hachulla, et $a l^{24}$. TTE was performed for most patients and was used to screen for PAH. The Bernoulli equation was used, when possible, to calculate the estimated systolic pulmonary artery pressure (sPAP). A maximal tricuspid regurgitant jet $>3.4 \mathrm{~m} / \mathrm{s}$ with or without an sPAP of $>50 \mathrm{mmHg}$ was indicative of PAH. Similarly, a tricuspid regurgitant jet $\leq 2.8 \mathrm{~m} / \mathrm{s}$ with or without an sPAP of $\leq 36 \mathrm{mmHg}$ was likely to rule out PAH. For sPAP ranging from $36 \mathrm{mmHg}$ to $50 \mathrm{mmHg}$, RHC was considered according to clinical findings and results from resting PFT.

Statistical analysis. Continuous variables are expressed as median values with their interquartile range. Extreme values were specified when appropriate. The chi-square test was used to study statistical relationships between qualitative variables. Observed concordance between diagnoses made either by CPET or reference investigations were expressed in percentages.
Spearman's rank coefficient was used to assess correlation between quantitative variables. McNemar's test with Yates's continuity correction was used to compare sensitivity and specificity between groups. P values of $<0.05$ were considered statistically significant using 2 -sided tests. Statistical analyses were performed with GraphPad Prism 6.2.

Ethics. Informed patient consent was gathered prior to CPET as part of routine clinical practice and data were anonymized by the attending physicians. In accordance with French regulation, approval by the institutional review board was not required but the data were collected, stored, and handled anonymously, as is usually the case in retrospective studies.

\section{RESULTS}

Clinical baseline data, resting PFT variables, and 6MWT. Thirty-one patients were initially screened in this bi-center, retrospective study. Four patients were subsequently excluded from the analysis because of the lack of clinical and imaging data $(\mathrm{n}=2)$ and for not meeting 2013 SSc ACR/EULAR criteria $(n=2$; Figure 1$)$. Twenty-seven patients were finally included in the analysis. Baseline patient characteristics are summarized in Table 1.

Data from resting PFT identified 7 cases of obstructive ventilator defects and 8 cases of restrictive ventilator defects. There were no "mixed" obstructive-restrictive patterns. The severity of the respiratory impairment did not always permit plethysmography. Table 2 provides baseline PFT and 6MWT data. Distances for 6MWT did not correlate with peak $\mathrm{VO}_{2}$, HR, or work rate. 
Table 1. Baseline characteristics of patients.

\begin{tabular}{|c|c|}
\hline Variables & $\mathrm{n}=27$ \\
\hline Center, Nice/Lille & $18 / 9$ \\
\hline Sex, female/male & $24 / 3$ \\
\hline Age, yrs, median (range) & $59(38-81)$ \\
\hline BMI, $\mathrm{kg} / \mathrm{m}^{2}$, median (IQR) & $25(22-28)$ \\
\hline History of smoking & 9 \\
\hline \multicolumn{2}{|l|}{ NYHA score } \\
\hline Class I & 3 \\
\hline Class II & 13 \\
\hline Class III & 8 \\
\hline Class IV & 3 \\
\hline $1 \mathrm{cSSc} / \mathrm{dcSSc}$ & $22 / 5$ \\
\hline Overlap syndromes & 5 \\
\hline \multicolumn{2}{|l|}{ Antibodies } \\
\hline Anticentromere & 9 \\
\hline Antitopoisomerase I & 11 \\
\hline Other & 10 \\
\hline Disease $\geq 5$ yrs & 16 \\
\hline Modified Rodnan score, median (IQR) & $4.5(2.0-12)$ \\
\hline Raynaud phenomenon & 26 \\
\hline Digital ulcers & 14 \\
\hline Telangiectasia & 16 \\
\hline Articular expression of the disease & 6 \\
\hline Gastroesophageal reflux disease & 17 \\
\hline Arterial hypertension & 7 \\
\hline History of SSc renal crisis & 0 \\
\hline Preexisting signs of right heart disease & 3 \\
\hline ECG conduction blocks & 8 \\
\hline Dry cough & 8 \\
\hline Hemoglobin, g/dl (IQR) & $12.40(12.08-13.73)$ \\
\hline Creatinine, $\mu \mathrm{mol} / \mathrm{l}$ (IQR) & $71(61-82)$ \\
\hline $\mathrm{BNP}<50 \mathrm{ng} / \mathrm{l}$ or NT-proBNP $<300 \mathrm{ng} / \mathrm{l}$ & 15 \\
\hline BNP 50-300 ng/l or NT-proBNP 300-1400 ng/l & 8 \\
\hline $\mathrm{BNP}>300 \mathrm{ng} / \mathrm{l}$ or NT-proBNP $>1400 \mathrm{ng} / \mathrm{l}$ & 0 \\
\hline
\end{tabular}

BMI: body mass index; IQR: interquartile range; NYHA: New York Heart Association; SSc: systemic sclerosis; lcSSc: limited cutaneous SSc; dcSSc: diffuse cutaneous SSc; BNP: brain natriuretic peptide; ECG: electrocardiograph; NT-proBNP: N terminal proBNP.

Data from reference investigations. CT scan diagnosis of ILD was possible in 18 cases, of which 8 were "extensive" forms. There was no evidence of venoocclusive disease. TTE suspected PAH in 7 cases and found LVD in 3 cases. Pericardial complications were absent. RHC was performed in 10 patients and diagnosed PAH in 6 cases. Cardiac MRI was performed in only 6 cases and identified myocardial scleroderma-related myocardial fibrosis in 1 patient.

CPET: overall assessment. CPET measurements are listed in Table 2. Maximal testing was achieved in 21 cases, but gas exchange profiles were interpretable for all 27 patients. We failed to obtain ABG sampling in 4 patients for technical reasons.

None of the subjects had normal CPET profiles. Aerobic capacity was reduced as highlighted by a median workload at $57 \%$ of its predicted value (equivalent to 3.7 metabolic equivalent of task). Further, the VeT could not be determined
Table 2. Summary of selected variables from resting PFT, 6MWT, and CPET.

\begin{tabular}{|c|c|c|}
\hline Variables & $\mathrm{n}$ & Median (IQR) \\
\hline \multicolumn{3}{|l|}{ Resting PFT } \\
\hline FEV1, 1 & 27 & $1.82(1.55-2.30)$ \\
\hline FEV $1, \%$ predicted & 27 & $81(67-101)$ \\
\hline FEV1/FVC, $\%$ & 27 & $77(69-101)$ \\
\hline FVC, 1 & 27 & $2.62(2.06-2.98)$ \\
\hline $\mathrm{FVC}, \%$ predicted & 27 & $92(72-107)$ \\
\hline TLC, $\%$ predicted & 17 & $83(62-94)$ \\
\hline $\mathrm{DLCO}, \mathrm{ml} / \mathrm{mn} / \mathrm{mmHg}$ & 26 & $11.25(7.87-16.01)$ \\
\hline DLCO, $\%$ predicted & 27 & $47(37-68)$ \\
\hline $\mathrm{KCO}, \%$ predicted & 27 & $60(47-84)$ \\
\hline \multicolumn{3}{|l|}{$6 \mathrm{MWT}$} \\
\hline Distance, $\mathrm{m}$ & 25 & $426(400-492)$ \\
\hline Distance (female patients), $\%$ predicted & 22 & $84(72-90)$ \\
\hline Distance (male patients), $\%$ predicted & 3 & $92(86-93)$ \\
\hline \multicolumn{3}{|l|}{ CPET } \\
\hline Peak work rate, $\%$ predicted & 27 & $57.00(50.00-79.80)$ \\
\hline VeT, $\%$ peak work rate & 23 & $38(25-55)$ \\
\hline $\mathrm{VO}_{2}$ peak, $\mathrm{ml} / \mathrm{kg} / \mathrm{mn}$ & 27 & $13(11-15)$ \\
\hline $\mathrm{VO}_{2}$ peak, $\%$ predicted & 27 & $62(53-78)$ \\
\hline MET peak & 27 & $3.7(3.0-4.4)$ \\
\hline MHR, $\%$ predicted & 27 & $80(74-90)$ \\
\hline$\Delta \mathrm{HR} / \Delta \mathrm{VO}_{2}$ peak, $\%$ & 27 & $79.30(61.20-101.90)$ \\
\hline $\mathrm{VO}_{2} / \mathrm{FC}$ peak, $\%$ predicted & 27 & $80(59-101)$ \\
\hline $\mathrm{P}(\mathrm{Ai}-\mathrm{a}) \mathrm{O}_{2}$ peak, $\%$ & 23 & $40.80(24.60-50.70)$ \\
\hline $\mathrm{P}(\mathrm{Ai}-\mathrm{a}) \mathrm{O}_{2}$ peak, $\%$ predicted & 23 & $200(111-274)$ \\
\hline $\mathrm{Vd} / \mathrm{Vt}$ peak, $\%$ predicted & 27 & $133(96-182)$ \\
\hline $\mathrm{VE} / \mathrm{VCO}_{2} \mathrm{VeT}, \%$ & 23 & $40.20(34.00-46.00)$ \\
\hline
\end{tabular}

PFT: pulmonary function tests; 6MWT: 6-minute walk test; CPET: cardiopulmonary exercise test; FEV1: forced expired volume in 1 second; FVC: forced vital capacity; TLC: total lung capacity; KCO: transfer coefficient (DLCO/alveolar volume); VeT: ventilatory threshold; $\mathrm{VO}_{2}$ : oxygen uptake; MET: metabolic equivalent of task; MHR: maximal heart rate; $\Delta \mathrm{HR} / \Delta \mathrm{VO}_{2}:\left(\mathrm{HR}_{\text {peak }}-\mathrm{HR}_{\text {rest }}\right)$ to $\left(\mathrm{VO}_{2 \text { peak }}-\mathrm{VO}_{2 \text { rest }}\right)$ ratio; $\mathrm{VO}_{2} / \mathrm{FC}$ : oxygen pulse; $\mathrm{P}(\mathrm{Ai}-\mathrm{a}) \mathrm{O}_{2}$ : alveolar-arterial gradient; $\mathrm{Vd} / \mathrm{Vt}$ : physiological dead space/tidal volume ratio; $\mathrm{VE} / \mathrm{VCO}_{2}$ : ventilatory equivalent for $\mathrm{CO}_{2}$.

in 4 cases. Often, a combination of putative mechanisms explained exercise limitation as illustrated by the Venn diagram (Figure 2). A single mechanism was identified in only 8 of the 27 tests.

Overall, we noted 16 CPET diagnoses of ILD, 15 PV, and 5 LVD. Of interest, PML, as implied by impaired peripheral oxygen extraction, was predominantly observed $(n=19)$. There was not any statistical relationship between longterm glucocorticoid intake and PML ( $\mathrm{p}=1.00)$.

Validity of CPET findings. There was a statistically significant negative correlation between DLCO (percent of predicted) and peak $\mathrm{P}(\mathrm{Ai}-\mathrm{a}) \mathrm{O}_{2}(\mathrm{r}=-0.71 ; 95 \% \mathrm{CI}-0.87$ to -0.39 , $\mathrm{p}=$ $0.0002)$, and between DLCO and peak $\mathrm{Vd} / \mathrm{Vt}(\mathrm{r}=-0.42 ; 95 \%$ CI -0.70 to $-0.36, p=0.0292$ ). CPET identified impaired lung function in 4 subjects with normal DLCO values. Further, there was a negative tendency between $\mathrm{KCO}$ and $\mathrm{P}(\mathrm{Ai}-\mathrm{a}) \mathrm{O}_{2}(\mathrm{r}=-0.43 ; 95 \% \mathrm{CI}-0.72$ to $0.0085, \mathrm{p}=0.0483)$. The other variables of resting PFT did not significantly correlate with those of CPET. 


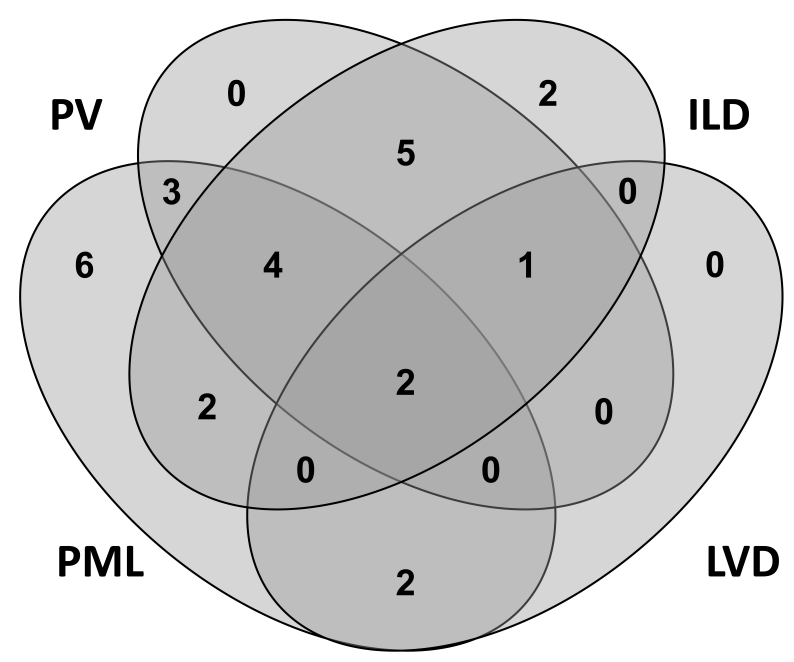

Figure 2. Venn diagram illustrating the various combinations of CPET diagnoses presented by the patients. There were 15 cases of PV, 16 cases of ILD, 19 cases of PML, and 5 cases of LVD. CPET: cardiopulmonary exercise testing; ILD: interstitial lung disease; PV: pulmonary vasculopathy; PML: peripheral/muscular limitation; LVD: left ventricular dysfunction.

A concordance of $80 \%$ between CPET and RHC for the diagnosis of PAH appeared to be superior to that which was calculated for TTE in relation to RHC (Table 3). CPET was able to identify patients with measured mean PAP at rest (mPAP) $\geq$ to $21 \mathrm{mmHg}$ (90\% concordance with RHC). Similarly, a concordance of $78 \%$ was observed between CPET and chest CT scan for the identification of ILD. For "extensive" forms of ILD, there was a 100\% concordance between both techniques. CPET did, however, identify additional ILD profiles in 2 patients with normal CT scans. In both cases, exercise testing was maximal and there was no evidence of PAH. ILD was overlooked by CPET analysis in 3 cases when the effort was not maximal and in 1 case of PAH. On the other hand, CPET had an excellent negative predictive value for the diagnosis of LVD (Table 3). Positive predictive values for CPET diagnoses were at least $80 \%$.
Diagnostic performances of CPET and the reference investigations for ILD, PAH, and LVD were comparable.

Further assessment of PML. Table 4 compares 3 subgroups of patients based on selected CPET variables and DLCO. These subgroups were (A) patients with exclusively a PML profile $(\mathrm{n}=6)$; $(\mathrm{B})$ those with PML or PML-associated exercise limitations $(\mathrm{n}=19)$; and $(\mathrm{C})$ those without PML $(n=8)$. Patients could not be classified based on ventilatory and cardiovascular variables alone. Neither the $\mathrm{VE} / \mathrm{VCO}_{2}$ (at VeT) ratio nor the difference $\mathrm{PetCO}_{2}(\mathrm{VeT})-\mathrm{PetCO}_{2}$ (offset; or $\left.\triangle \mathrm{PetCO}_{2}\right)$ - taken independently - could differentiate between patients with or without PAH. Only $\mathrm{P}(\mathrm{Ai}-\mathrm{a}) \mathrm{O}_{2}$ and DLCO helped to distinguish subjects with ILD from those without ILD ( $<<0.05)$.

\section{DISCUSSION}

Our study reflects daily medical practices and demonstrates that CPET can accurately identify competing mechanisms in patients with SSc presenting with limited exercise capacity. CPET has an added value compared to resting PFT for suggesting ILD, including in cases in which CT imaging is unremarkable. Our results also suggest that peripheral/ muscular limitation is highly prevalent in patients with SSc. Validity of CPET interpretation. The interpretation of CPET relies on a pattern-based integrative approach. Our findings illustrate the importance of variables at maximal exercising such as $\mathrm{P}(\mathrm{Ai}-\mathrm{a}) \mathrm{O}_{2}$ and $\mathrm{Vd} / \mathrm{Vt}$ that require $\mathrm{ABG}$ at the peak of exercise. We were able to show that peak $\mathrm{P}(\mathrm{Ai}-\mathrm{a}) \mathrm{O}_{2}$ correlates negatively with resting DLCO. This is a common finding in ILD, including in SSc, that helps to validate the quality of our data $5,25,26$. We have also shown that $\mathrm{VE} / \mathrm{VCO}_{2}(\mathrm{VeT})$ and $\Delta \mathrm{PetCO}$ alone are not sufficiently accurate for the analysis of multifactorial etiology of exercise limitation. These variables have been extensively studied, including in SSc, but they fail to quantitate and appropriately classify etiologies when combined exercise limitation is suspected ${ }^{6,27,28}$. For instance, the increase in $\mathrm{VE} / \mathrm{VCO}_{2}$ generally results from an increase in dead space

Table 3. Agreement (concordance) and validity of investigations.

\begin{tabular}{lccccc}
\hline Variable tested & mPAP $\geq 25 \mathrm{mmHg}$ & mPAP $\geq 25 \mathrm{mmHg}$ & mPAP, $\geq 21 \mathrm{mmHg}$ & ILD & LVD \\
\hline Reference investigation & RHC & RHC & RHC & Chest CT scan \\
No. subjects & 10 & 10 & 10 & 27 & TTE \\
Diagnostic method & CPET & TTE & CPET & CPET & CPET \\
Observed concordance & $80 \%$ & $70 \%$ & $90 \%$ & $96 \%$ \\
Sensitivity (CI 95\%) & $0.86(0.42-1.0)$ & $0.67(0.22-0.96)$ & $0.89(0.52-1.0)$ & $0.78(0.52-0.94)$ & $1.00(0.29-1.0)$ \\
Specificity (CI 95\%) & $0.67(0.094-0.99)$ & $0.75(0.19-0.99)$ & $1.0(0.025-1.0)$ & $0.78(0.40-0.97)$ & $0.96(0.79-1.0)$ \\
PPV (CI 95\%) & $0.86(0.42-1.0)$ & $0.8(0.28-0.99)$ & $1.0(0.63-1.0)$ & $0.88(0.62-0.98)$ & $0.75(0.19-0.99)$ \\
NPV (CI 95\%) & $0.67(0.094-0.99)$ & $0.6(0.15-0.95)$ & $0.5(0.013-0.99)$ & $0.64(0.31-0.89)$ & $1.0(0.85-1.0)$ \\
McNemar, p value & 0.48 & 1.00 & 1.00 & 0.68 & 1.00 \\
\hline
\end{tabular}

P value for McNemar's test with Yates' continuity correction (comparisons between diagnostic method and its reference investigation). mPAP: mean pulmonary arterial pressure; ILD: interstitial lung disease; LVD: left ventricular dysfunction; RHC: right heart catheterization; CT: computed tomography; TTE: transthoracic echocardiogram; CPET: cardiopulmonary exercise test; PPV: positive predictive value; NPV: negative predictive value.

Personal non-commercial use only. The Journal of Rheumatology Copyright $\odot$ 2018. All rights reserved 
Table 4. Comparison of 3 subgroups of patients based on selected CPET variables and DLCO. Group A patients are those with exclusively a PML profile (n = 6), Group B are those with PML or PML-associated exercise limitations ( $\mathrm{n}=19)$, and Group C are those without PML ( $\mathrm{n}=8$ ). Median values with their IQR are given.

\begin{tabular}{|c|c|c|c|c|c|c|c|}
\hline & & \multirow[t]{2}{*}{ Group A } & \multirow[t]{2}{*}{ Group B } & \multirow[t]{2}{*}{ Group C } & \multicolumn{3}{|c|}{$\mathrm{p}$} \\
\hline & & & & & A vs B & A vs C & $\mathrm{B}$ vs $\mathrm{C}$ \\
\hline \multicolumn{8}{|c|}{ Metabolic variables } \\
\hline $\mathrm{nv}=33$ & MET & $4.4(3.7-5.4)$ & $3.7(3.0-4.4)$ & $3.6(3.0-4.8)$ & ns & ns & ns \\
\hline $\mathrm{nv}=33$ & $\mathrm{VO}_{2}($ peak) $\mathrm{ml} / \mathrm{kg}$ & $71.5(62.3-78.5)$ & $68(54-78)$ & $57.0(44.8-83.5)$ & ns & ns & ns \\
\hline \multicolumn{8}{|c|}{ Ventilatory variables } \\
\hline $\mathrm{nv}=28$ & $\mathrm{VE} / \mathrm{VCO}_{2}(\mathrm{VeT}), \%$ predicted & $40.2(31.7-44.5)$ & $39.6(33.4-45.3)$ & $41.0(35.0-46.0)$ & ns & ns & ns \\
\hline $\mathrm{nv}=33$ & $\mathrm{Vd} / \mathrm{Vt}$ (peak) \%predicted & $108.5(77.43-152.0)$ & $127.4(94.7-163.3)$ & $166.2(99.5-228.0)$ & ns & ns & ns \\
\hline \multicolumn{8}{|c|}{ Cardiovascular variables } \\
\hline $\mathrm{nv}=33$ & $\Delta \mathrm{HR} / \Delta \mathrm{VO}_{2}, \%$ & $73.6(57.2-91.1)$ & $87.5(66.1-102.0)$ & $63.1(57.2-99.3)$ & ns & ns & ns \\
\hline $\mathrm{nv}=33$ & $\mathrm{VO}_{2} / \mathrm{HR}$ (peak), $\%$ predicted & $92.5(80.5-107.8)$ & $80.0(60.0-103.0)$ & $75.0(58.0-91.8)$ & ns & ns & ns \\
\hline \multicolumn{8}{|c|}{ Gas exchange variables } \\
\hline $\mathrm{nv}=33$ & $\mathrm{P}(\mathrm{Ai}-\mathrm{a}) \mathrm{O}_{2}(\text { peak })^{*}, \%$ predicted & $101.0(66.0-125.5)$ & $127.0(98.0-262.0)$ & $250.5(188.8-323.8)$ & 0.6621 & 0.0177 & 0.0684 \\
\hline $\mathrm{nv}=28$ & $\mathrm{PetCO}_{2}(\mathrm{VeT}), \mathrm{mmHg}$ & $35.0(29.0-38.5)$ & $38.5(33.4-42.8)$ & $32.0(28.9-35.8)$ & ns & ns & ns \\
\hline $\mathrm{nv}=33$ & Resting DLCO**,\%predicted & $68.0(56.5-82.3)$ & $64.0(37.0-73.0)$ & $44.0(25.0-53.0)$ & 0.7625 & 0.0498 & 0.2140 \\
\hline
\end{tabular}

* P value for the Kruskal-Wallis test: 0.0120 .** P value for the Kruskal-Wallis test: 0.0478 . CPET: cardiopulmonary exercise test; PML: peripheral/muscular limitation; MET: metabolic equivalent of task; VeT: ventilatory threshold; $\mathrm{VO}_{2}$ (peak): oxygen uptake at peak exercise; $\mathrm{HR}$ : heart rate; $\Delta \mathrm{HR} / \Delta \mathrm{VO}$ : $\left(\mathrm{HR}_{\text {peak }}-\mathrm{HR}_{\text {rest }}\right)$ to $\left(\mathrm{VO}_{2 \text { peak }}-\mathrm{VO}_{2 \text { rest }}\right)$ ratio; $\mathrm{VE} / \mathrm{VCO}_{2}(\mathrm{VeT})$ : ventilatory equivalent for $\mathrm{CO}_{2}$ at $\mathrm{VeT} ; \mathrm{Vd} / \mathrm{Vt}$ (peak): physiological dead space/tidal volume ratio at peak exercise; $\mathrm{P}(\mathrm{Ai}-\mathrm{a}) \mathrm{O}_{2}$ (peak): alveolar-arterial gradient at peak exercise; $\mathrm{PetCO}_{2}$ (VeT): end tidal $\mathrm{CO}_{2}$ pressure at VeT; nv: no. values; ns: non-significant; \% predicted: percent of predicted value; IQR: interquartile range.

ventilation that is seen in cases of ILD, PAH, and even $\mathrm{LVD}^{6,22,29}$. Unlike Dumitrescu, et $a l^{6}$, we believe that $\mathrm{VE} / \mathrm{VCO}_{2}$ cannot distinguish PAH from LVD in patients with $\mathrm{SSc}$ and that $\mathrm{PetCO}_{2}$ is, more often than not, underestimated in hyperventilating patients 22 . To the best of our knowledge, ours is the first study that considers the multifaceted aspect of exercise limitation in SSc, unlike previous works that chose to identify and characterize the predominant mechanism.

There was an excellent concordance between the diagnoses made by CPET and results from the reference investigations. This strengthens our belief that its sensitivity makes CPET an appropriate tool for identifying SSc-related cardiovascular, respiratory, and peripheral complications.

Early diagnosis of $P V$ and ILD. CPET can provide better knowledge of SSc-associated PAH through the study of gas exchange profiles on consecutive tests. In fact, diagnosis of $\mathrm{PV}$ in patients who were not suspected of having PAH on TTE was established based on CPET profiles ${ }^{6}$. In our study population, CPET suggested PV in patients who had an mPAP of $21 \mathrm{mmHg}$ or higher assessed by RHC. One should bear in mind that the clinical significance of mPAP between $21 \mathrm{mmHg}$ and $24 \mathrm{mmHg}$ is unclear and that close followup is currently recommended for patients with connective tissue disorders and/or family history of $\mathrm{PAH}^{30,31}$. Further, when associated with systematic exercise RHC, CPET was able to identify ILD, PAH, and LVD in patients with SSc limited exercise capacity ${ }^{7}$. Our study further suggests that CPET might be used to better identify patients who require RHC a diagnostic procedure that is not without risks.

Resting PFT could underestimate lung involvement in
$\mathrm{SSc}^{32}$. Reduced DLCO has been shown to be an excellent predictor of $\mathrm{PAH}$, especially in patients with $\mathrm{lcSSc}$, but it also happens to be associated with $\operatorname{ILD}^{33,34,35}$. Widened $\mathrm{P}(\mathrm{Ai}-\mathrm{a}) \mathrm{O}_{2}$ at peak exercise, when considered independently, can help separate ILD and early PV from LVD and peripheral vascular limitations. This is in keeping with the analysis by Walkey, et $a l^{7}$. Similarly, Schwaiblmair, et al have shown that CPET was superior to resting PFT in predicting cardiopulmonary abnormalities ${ }^{5}$. This is reflected in our series: widened $\mathrm{P}(\mathrm{Ai}-\mathrm{a}) \mathrm{O}_{2}$ identified 4 patients with ILD and/or PV for whom resting lung volumes and DLCO were normal. Our findings are also compatible with what has been previously described in the early detection of idiopathic pulmonary fibrosis (IPF) with CPET $^{36}$.

Early detection of ILD, however, can be challenging when CPET is submaximal or when competing factors lead to its premature discontinuation prior to the widening of $\mathrm{P}(\mathrm{Ai}-\mathrm{a}) \mathrm{O}_{2}$. This, in part, explains the imperfect diagnostic concordance between CT imaging and CPET in our series.

Peripheral impairment. We found that most of the patients in our series had abnormal peripheral oxygen-extraction and oxygen-transport profiles that suggested circulatory and/or muscular limitations. In several patients, the reduction of work rate, a decreased peak $\mathrm{VO}_{2}$ and lower VeT (in some cases, its absence) were suggestive of substantial exercise limitation and muscle hypoxia. To our knowledge, circulatory impairment to exercise in SSc has only been addressed in a study by Sudduth, et al, but has not been further characterized $^{37}$. Despite the relatively small study population (15 patients), the authors of that study had the merit of highlighting a lesser known and often underestimated cause

Personal non-commercial use only. The Journal of Rheumatology Copyright $@$ 2018. All rights reserved 
of exercise limitation in SSc. The cause of this peripheral limitation remains difficult to assess. Fick's equation $\left[\mathrm{VO}_{2}\right.$ $=\mathrm{HR} \times \mathrm{SV} \times \mathrm{D}(\mathrm{a}-\mathrm{v}) \mathrm{O}_{2}$ ] exposes the limits of the interpretation of CPET profiles, because the diagnostic approach does not take into account $\mathrm{D}(\mathrm{a}-\mathrm{v}) \mathrm{O}_{2}-\mathrm{a}$ variable that cannot be measured in the clinical setting. It is highly probable that $\mathrm{D}(\mathrm{a}-\mathrm{v}) \mathrm{O}_{2}$ is affected by an SSc-related systemic vasculopathy.

Muscle involvement has rarely been studied other than in SSc-related myositis ${ }^{38}$. Muscle histological studies, when performed, usually describe nonspecific myositis and necrotizing myositis, often associated with angular atrophic esterase-positive fibers ${ }^{39}$. None of the patients in our series had biological evidence of myolysis and none presented with clinical myositis. Peripheral limitation in SSc can be explained not only by associated myopathy and deconditioning, but also by subclinical profibrotic manifestations. Interestingly, previous studies have shown that muscle involvement in SSc impairs survival and is associated with cardiorespiratory complications ${ }^{40,41}$. Early detection of PML can lead to an early implementation of respiratory and muscular rehabilitation.

Limits. The major limit of our study is its retrospective design and the lack of standardized procedures. However, reappraisal of each case by an expert respiratory specialist substantiated the initial CPET diagnoses. For clarity's sake, we opted to consider the 4 etiologies that are presented in this paper. Exercise limitation being multifactorial, the clinical context was taken into account when assessing the importance of 1 mechanism over another. Missing clinical and biological data were more problematic. For instance, complete serological profiles of SSc (i.e., anti-PM-Scl or anti-RNA-polymerase III antibodies) and echocardiographic variables (i.e., right atrial surface) that may have helped us further classify patients were lacking. Patients included in our study had various treatments whose modifications were not always clearly outlined in medical records. We were therefore unable to study the effect of CPET on therapeutic decisions.

The number of subjects in our series is modest and reflects difficulties in recruiting patients with rare diseases, as seen in other studies on CPET in SSc. Selection bias is limited even though there is an overrepresentation of lcSSc (in keeping with its prevalence) that did not permit the comparison of CPET profiles between lcSSc and dcSSc forms.

Our study demonstrates that CPET is useful in the diagnostic investigation of exercise limitation in patients with SSc. It is a noninvasive technique that provides information that is not available with more conventional diagnostic strategies and it can lead to modifications in treatment. Additionally, normal CPET profiles could reduce unnecessary examinations. Longterm followup with serial CPET might identify early pulmonary or vascular impairment.
Finally, peripheral impairment is probably underestimated in patients with SSc. For this reason, the effect of cardiorespiratory rehabilitation needs to be further studied.

\section{REFERENCES}

1. Hachulla E, Czirják L. EULAR textbook on systemic sclerosis. London: BMJ Publishing Group Limited; 2013.

2. Owens GR, Follansbee WP. Cardiopulmonary manifestations of systemic sclerosis. Chest 1987;91:118-27.

3. Tyndall AJ, Bannert B, Vonk M, Airò P, Cozzi F, Carreira PE, et al. Causes and risk factors for death in systemic sclerosis: a study from the EULAR Scleroderma Trials and Research (EUSTAR) database. Ann Rheum Dis 2010;69:1809-15.

4. American Thoracic Society, American College of Chest Physicians. ATS/ACCP Statement on cardiopulmonary exercise testing. Am J Respir Crit Care Med 2003;167:211-77.

5. Schwaiblmair M, Behr J, Fruhmann G. Cardiorespiratory responses to incremental exercise in patients with systemic sclerosis. Chest 1996;110:1520-5.

6. Dumitrescu D, Oudiz RJ, Karpouzas G, Hovanesyan A, Jayasinghe A, Hansen JE, et al. Developing pulmonary vasculopathy in systemic sclerosis, detected with non-invasive cardiopulmonary exercise testing. PLoS One 2010;5:e14293.

7. Walkey AJ, Ieong M, Alikhan M, Farber HW. Cardiopulmonary exercise testing with right-heart catheterization in patients with systemic sclerosis. J Rheumatol 2010;37:1871-7.

8. van den Hoogen F, Khanna D, Fransen J, Johnson SR, Baron M, Tyndall A, et al. 2013 classification criteria for systemic sclerosis: an American college of rheumatology/European league against rheumatism collaborative initiative. Ann Rheum Dis 2013; 72:1747-55.

9. LeRoy EC, Medsger TA. Criteria for the classification of early systemic sclerosis. J Rheumatol 2001;28:1573-6.

10. Clements PJ, Lachenbruch PA, Seibold JR, Zee B, Steen VD, Brennan P, et al. Skin thickness score in systemic sclerosis: an assessment of interobserver variability in 3 independent studies. J Rheumatol 1993;20:1892-6.

11. Wanger J, Clausen JL, Coates A, Pedersen OF, Brusasco V, Burgos F, et al. Standardisation of the measurement of lung volumes. Eur Respir J 2005;26:511-22.

12. Miller MR, Hankinson J, Brusasco V, Burgos F, Casaburi R, Coates A, et al. Standardisation of spirometry. Eur Respir J 2005;26:319-38.

13. Macintyre N, Crapo RO, Viegi G, Johnson DC, van der Grinten CP, Brusasco V, et al. Standardisation of the single-breath determination of carbon monoxide uptake in the lung. Eur Respir J 2005;26:720-35.

14. ATS Committee on Proficiency Standards for Clinical Pulmonary Function Laboratories. ATS statement: guidelines for the six-minute walk test. Am J Respir Crit Care Med 2002;166:111-7.

15. Enright PL, Sherrill DL. Reference equations for the six-minute walk in healthy adults. Am J Respir Crit Care Med 1998; 158:1384-7.

16. Huszczuk A, Whipp BJ, Wasserman K. A respiratory gas exchange simulator for routine calibration in metabolic studies. Eur Respir J 1990;3:465-8.

17. Cooper CB. Exercise testing and interpretation: a practical approach. Cambridge, UK: Cambridge University Press; 2001.

18. Jones N. Clinical exercise testing, 4th ed. Philadelphia: Saunders; 1997.

19. Sullivan MJ, Cobb FR. The anaerobic threshold in chronic heart failure. Relation to blood lactate, ventilatory basis, reproducibility, and response to exercise training. Circulation 1990;81 Suppl 1: II47-58.

20. Beaver WL, Wasserman K, Whipp BJ. A new method for detecting anaerobic threshold by gas exchange. J Appl Physiol 1986; 60:2020-7. 
21. Hansen JE, Sue DY, Wasserman K. Predicted values for clinical exercise testing. Am Rev Respir Dis 1984;129:S49-55.

22. Wasserman K, Hansen JE, Sue DY, Stringer WW, Sietsema KE, Sun $\mathrm{XG}$, et al. Principles of exercise testing and interpretation: including pathophysiology and clinical applications, 5th ed. Philadelphia: Lippincott Williams and Williams; 2011.

23. Goh NS, Desai SR, Veeraraghavan S, Hansell DM, Copley SJ, Maher TM, et al. Interstitial lung disease in systemic sclerosis: a simple staging system. Am J Respir Crit Care Med 2008; 177:1248-54

24. Hachulla E, de Groote P, Gressin V, Sibilia J, Diot E, Carpentier P, et al. The three-year incidence of pulmonary arterial hypertension associated with systemic sclerosis in a multicenter nationwide longitudinal study in France. Arthritis Rheum 2009;60:1831-9.

25. Nordenfelt I, Svensson G. The transfer factor (diffusing capacity) as a predictor of hypoxaemia during exercise in restrictive and chronic obstructive pulmonary disease. Clin Physiol Oxf Engl 1987; 7:423-30.

26. Agusti AG, Roca J, Rodriguez-Roisin R, Xaubet A, Agusti-Vidal A. Different patterns of gas exchange response to exercise in asbestosis and idiopathic pulmonary fibrosis. Eur Respir J 1988;1:510-6.

27. Sun XG, Hansen JE, Garatachea N, Storer TW, Wasserman K. Ventilatory efficiency during exercise in healthy subjects. Am J Respir Crit Care Med 2002;166:1443-8.

28. Rosato E, Romaniello A, Magrì D, Bonini M, Sardo L, Gigante A, et al. Exercise tolerance in systemic sclerosis patients without pulmonary impairment: correlation with clinical variables. Clin Exp Rheumatol 2014;32:S103-8.

29. Chua TP, Ponikowski P, Harrington D, Anker SD, Webb-Peploe K, Clark AL, et al. Clinical correlates and prognostic significance of the ventilatory response to exercise in chronic heart failure. J Am Coll Cardiol 1997;29:1585-90.

30. Hoeper MM, Bogaard HJ, Condliffe R, Frantz R, Khanna D, Kurzyna M, et al. Definitions and diagnosis of pulmonary hypertension. J Am Coll Cardiol 2013;62:D42-50.

31. Galiè N, Humbert M, Vachiery JL, Gibbs S, Lang I, Torbicki A, et al. 2015 ESC/ERS Guidelines for the diagnosis and treatment of pulmonary hypertension. Eur Heart J 2016;37:67-119.
32. Suliman YA, Dobrota R, Huscher D, Nguyen-Kim TD, Maurer B, Jordan S, et al. Brief report: pulmonary function tests: high rate of false-negative results in the early detection and screening of scleroderma-related interstitial lung disease. Arthritis Rheumatol 2015;67:3256-61.

33. Steen V. Predictors of end stage lung disease in systemic sclerosis. Ann Rheum Dis 2003;62:97-9.

34. Remy-Jardin M, Remy J, Wallaert B, Bataille D, Hatron PY. Pulmonary involvement in progressive systemic sclerosis: sequential evaluation with CT, pulmonary function tests, and bronchoalveolar lavage. Radiology 1993;188:499-506.

35. Diot E, Boissinot E, Asquier E, Guilmot JL, Lemarié E, Valat C, et al. Relationship between abnormalities on high-resolution CT and pulmonary function in systemic sclerosis. Chest 1998;114:1623-9.

36. Agustí C, Xaubet A, Agustí AG, Roca J, Ramirez J, Rodriguez-Roisin R. Clinical and functional assessment of patients with idiopathic pulmonary fibrosis: results of a 3 year follow-up. Eur Respir J 1994;7:643-50.

37. Sudduth CD, Strange C, Cook WR, Miller KS, Baumann M, Collop NA, et al. Failure of the circulatory system limits exercise performance in patients with systemic sclerosis. Am J Med 1993;95:413-8.

38. Mimura Y, Ihn H, Jinnin M, Asano Y, Yamane K, Tamaki K. Clinical and laboratory features of scleroderma patients developing skeletal myopathy. Clin Rheumatol 2005;24:99-102.

39. Paik JJ, Wigley FM, Lloyd TE, Corse AM, Casciola-Rosen L, Shah $\mathrm{AA}$, et al. Spectrum of muscle histopathologic findings in forty-two scleroderma patients with weakness. Arthritis Care Res 2015;67:1416-25.

40. Jung M, Bonner A, Hudson M, Baron M, Pope JE, Canadian Scleroderma Research Group (CSRG). Myopathy is a poor prognostic feature in systemic sclerosis: results from the Canadian Scleroderma Research Group (CSRG) cohort. Scand J Rheumatol 2014;43:217-20.

41. Follansbee WP, Zerbe TR, Medsger TA. Cardiac and skeletal muscle disease in systemic sclerosis (scleroderma): a high risk association. Am Heart J 1993;125:194-203. 